\title{
Neutral Monism and Conceptions of Historiosofical Synthesis as Methodology of History
}

\author{
Larionova, I.L. \\ Ph.D., Associate Professor, National Research University Higher School of Economics, \\ Faculty of History, Department of the History of Ideas and Methods of Historical Research, Moscow, Russia \\ E-mail: irinallarionova@rambler.ru
}

\author{
Doi:10.5901/ajis.2013.v2n8p146
}

\section{Abstract}

Examination of issues related to the methodology of history is important in connection with discussions of the theoretical component of historical knowledge. We consider that the methodology of history is an aggregate of philosophical, historical, and universal scientific conceptions, which can be presented as an integrated system with aspects and levels. There are ontological, epistemological, and axiological aspects of historical methodology. From the ontological perspective, researchers are trying to define the historical reality and the way how this reality evolves. Ontological aspect consists of doctrines of being (low-level), universal scientific theories, including theories of evolution (mid-level), historiosophical conceptions of world history (top-level), special historiosophical and general historical conceptions (additional and special methodology). The aim of this article is to find what doctrines of being and what historiosaphical conceptions of the world history may be considered as constructive methodology of history in the framework of its ontological aspect nowadays. For this purpose, we examine ontological doctrines and historiosaphical conceptions of the world history and determine what kinds of them are consistent with the key principles of evolution of great open systems, established by synergetics as a modern theory of evolution. We prove that evolutionary version of neutral monism and conceptions of historiosothical synthesis collocate with the key principles of synergetics to the gratis extend.

Keywords: methodology of history, philosophy of history, synergetics, neutral monism

\section{Introduction}

Nowadays, when the historical science has accumulated a large amount of historical information, historians, philosophers, mathematicians, and other scientists are actively discussing the theoretical perspectives of history.

Many authors think that theoretical history cannot exist at all. The tradition pioneered by W. Dilthey, was further developed in the philosophy of postmodernism. Rationalistic interpretation of the opposition of the humanities and the natural sciences is the most clearly represented by the works of Karl Popper (Popper, 1979). Popper believes that since humanity is a single phenomenon, revealing the laws of its evolution is impossible. However, the natural sciences, such as astronomy, for instance, sometimes face similar problems (Metagalaxy is a single phenomenon).

Among the researchers who consider that theoretical history is possible, there is no consensus on what it should include. Some scholars believe that the theoretical history should be a system of mathematical models describing different historical processes (Kapitsa, Kurdyumov, and Malinetskiy, 2003;; Turchin, 2003; Grinin, 2006; Korotaev, Malkov, and Halturina, 2010; Budanov, 2013 and other). According to other researchers, the theoretical history does not have to be like modern physics. Nevertheless, its theories must be falsifiable and verifiable (Rozov, 2002; Knyazeva, Kurdyumov, 1994 and other).

We assume that theoretical history include hypothetically special historiosophic and general historical conceptions which are theoretical models of societies and historical processes, not necessarily expressed by mathematical language though. However, to be a part of the theory of historical knowledge, these models must comply with this or that scientific paradigm of the world history. Thus, to make theoretical history real, existing approaches to the interpretation of the world-historical process must move from the category of philosophical doctrines to the category of scientific theories. In addition, to implement this transition, the existing approaches to history must be in some way justified.

We believe that this transformation can be realized if historiosophical approaches are substantiated by universal scientific conceptions that are nowadays considered to be reliable. From this point of view, the most interesting is the general scientific theory of synergetics as a modern theory of evolution. Synergetics describes the development of complex open systems of different nature. Thus, the laws of the evolution of such systems should manifest themselves in the development of human society. 
However, the specific conceptions of world history (theories of Marx, Spengler, Toynbee, Rostow, Wallerstein, and others), which allow to identify the main approaches to the interpretation of the world-historical process, are complex. They offer answers to various questions concerning historical development, historical research, and evaluation of the past and the present. Answers to these questions are justified in different ways. Therefore, the formation of a theoretical history is impossible without determining the structure of the methodology of history.

One might suppose that methodology of history is an aggregate of philosophical, universal scientific and historical conceptions, which can be represented as an integrated system with aspects and levels.

In the framework of ontological aspect of the history methodology, philosophers, historians, and other scholars are trying to find an answer to the question what kind of phenomenon is historical reality and how this reality evolves. This aspect of the methodology combines doctrines of being, universal scientific theories, including scientific conceptions of evolution, historiosophical models of world history, special historiosophical and general historical conceptions.

Theoretical constructions which can be attributed to the epistemological aspect of historical methodology are created to solve the problem how people study society and its development. These theories form general epistemology, scientific epistemology, and historical epistemology. This aspect of the methodology also includes the theory of the specific techniques of historical research.

It can be noted that the historical methodology has an axiological aspect. Various conceptions that build this aspect do not focus on evaluation of historical phenomena and events. This aspect of the methodology holds general outlook, scientific outlook, political ideology, and the personal position of the authors of scientific papers.

Consequently, every aspect of the methodology can be presented as a system of four levels. In this case, the first level of the methodology of history includes general philosophical ontology, general epistemology, and general outlook, the second level is formed by universal scientific theories, a scientific epistemology, and a scientific outlook; the third level consists of historiosophical conceptions of the world history, historical epistemology, and political ideology. The fourth level embraces special historiosophical and general historical conceptions, the theory of the specific techniques of historical research and personal sets are used in the study.

We assume the first level, which is the most distant from the historical research, as a lower, the second level - as an average, and the third level - as an upper. It should be noted that historiosophical conceptions of the world history, historical epistemology, and political ideology play a pivotal role in direct methodology of historical research. These theories form a basis of complete history courses, whatever way they are set out (in the form of multi-volume works, textbooks or lecture cycles) and their specific instruments.

\section{Research objective}

We are to find what ontological doctrines and what historiosaphical conceptions of world history may be considered as constructive methodology of history within the framework of its ontological aspect nowadays, if we want to correlate them with the universal scientific theories.

In the history of philosophical thought one can identify five major types of philosophical conceptions: idealism, materialism, dualism, neutral monism, and ontology that do not consider the question of the relationship between the mental and the physical. Therefore, we tend to substantiate one of these paradigms as a lower level of historical methodology.

There are three main types of conceptions of the world-historical process in the history of historiosophical thought. One might notice a stadial approach to history, civilizational approach to history, and an approach of historiosophical synthesis. We intend to choose one of them as a top-level methodology of history.

\section{Methodology}

\subsection{Method of determining the type of ontology}

First, we analyze the main types of ontological doctrines in terms of their rationality and internal consistency because irrational and controversial theories are not suitable for the role of the low-level methodology of history. Next, we examine the conceptions of being, which passed this critical analysis, and we try to determine what kind of them are in accordance with the key principles of synergetics. These philosophical doctrines are also considered in order to define their compliance with modern scientific conceptions of evolution of the Universe and the discoveries that correspond to these theories. Thus, we can say that the ontological doctrines are considered in their relations to the principles of 
rationality, consistency, and evolutionism.

\subsection{Method of selecting the type of historiosophical paradigm}

Considering the main approaches to the interpretation of world history, we correlate the key principles of synergetics with the various aspects of these approaches, and try to establish which historiosaphical paradigm is the most consistent with universal principles of evolution.

\section{Analyses}

\subsection{Basic ontological paradigms in their relation to the principles of rationality, consistency, and modern evolutionism}

In the history of philosophical thought, we can see five major types of philosophical conceptions of being. This is such ontology as materialism, idealism, dualism, neutral monism, and the ontological perspective, not intended to answer the question of relationship between the mental and the physical. The most consistent ontology, which needs no solutions to the problem, is existentialism (Martin Heidegger, Karl Theodor Jaspers, Jean-Paul Sartre and others). We believe that irrational paradigm cannot be considered as a low-level methodology of history, if history and its methodology are conceived as rational phenomena, and general scientific theories are proposed as mid-level historical methodology. All other types of ontology are rationalistic.

According to dualism (Plato, Descartes, Karl Popper, Richard Swinburne and others), there are two substances (two fully independent entities) - the mental and the physical. This ontology has a certain intuitive appeal and some support in the modern psychology and physiology (Priest, 1991 p.6-7). The main stumbling block of dualism is a problem of psycho-physical interaction. It is not clear how the mental and the physical can communicate with each other, being completely different entities (Priest, 1991 p.31-34). Thus, dualism is an internally controversial ontology and, therefore, unsuitable for the role of historical methodology.

There are no insurmountable logic problems in the monistic conceptions. Let us address the monistic ontology and consider materialism, idealism, and neutral monism in terms of their relations to the modern science and the principle of evolutionism.

Idealism (Plotinus, George Berkeley, Johann Gottlieb Fichte, Friedrich Wilhelm Schelling and other) claims that the mind is the only substance. Physical objects are not material and do not exist independently from human perception. Reason for the existence of physical objects is God, or single human minds. Stephan Priest pays attention to the following argument in favor of idealism: we know that physical things exist just because we see them; but the fact that we have a perceptual experience of physical objects does not result in that they are there when we do not see them (Priest, 1991 p.70). Let us note that this argument finds some support in modern physics. Discovered in the second half of the 20th century, the quantum Zeno effect declaims that the unstable particle in an ideal continuous monitoring can never break up (Halfin, 1990). Thus, the existence of an object is directly determined by the fact of his observations. However, the Zeno effect is not fixed in the macrocosm.

Materialism (Democritus, Thomas Hobbes, Paul-Henry Holbach, Ludwig Feuerbach, U.T. Place, David Armstrong and others) suggests that there is only matter and its properties. Physical objects are composed of matter; exist in space and time, have the shape, size, density, and they are able to move. Mental phenomena are material or identical with brain states, or are properties of physical objects. According to Priest, the strength of materialism is the characteristic of properties of physical objects (Priest, 1991 p.98). However, it should be stated that many of these features are not suitable for the description of fields, especially for the description of the physical vacuum. If modern physics supports idealism, it cannot provide arguments in favor of materialism.

Let us turn our attention to the fact that the classical idealism and the classical materialism are not evolutionary conceptions, since both types of ontology state that the only substance is eternal and constant.

Neutral monism (Anaximander, Benedictus Spinoza, Bertrand Russell, and Peter Strawson) suggests that the physical and the mental are two forms or two aspects or two properties of a single reality which is neither matter nor consciousness, but contains both possibilities. Let us consider some conceptions that seem to be attributed to neutral monism.

According to Anaximander, the substantial and the genetic origin of the world is apeiron (something unlimited in quantity and quality). Apeiron is the essence of the elements - earth, water, air, and fire, which can turn one into another. All things arise from Apeiron, and everything will come back to it (Anaximander, 1969). Apeiron is divine (eternal and 
immortal), "embraces everything and controls everything." All the worlds are in apeiron (Russell, 1946 p.60). It is not clear whether there are Anaximander's worlds simultaneously or sequentially (Finkelberg, 1994), perhaps both assumptions are correct. Russell held that Anaximander was the most interesting philosopher among the Milesans with his views that the primal substance was supposed to be neutral (Russell, 1946 p.45-46).

Let us note that such neutral entity like apeiron is the essence of the physical elements and controls everything as the divine mind. This implies that it has mental and physical aspects. Thanks to this specificity, apeiron can generate matter and mind. Thus, Anaximander's universe evolves. If apeiron can be interpreted as a substance containing the possibility of the physical (four elements) and the mental (living, according to Anaximander, eventually arises from nonliving, people come from animals), it is an evolutionary version of neutral monism. Once the primal substance was in its original state, then it was neutral, but it also had an opportunity of generating the physical and the mental. Nowadays, this substance, maintaining its neutrality, exists in the elements and things, including human with his mind. In future times, four elements and the variety of things, including people, will dissolve in apeiron again.

Some features of Anaximander's conception partly correspond to some principles of synergetics. At first glance, Anaximander's apeiron cannot be identified with any modern concept. However, it can be assumed that apeiron has some properties of chaos, that chaos and apeiron are similar concepts. According to V.G Budanov, in the evolution of complex open system one can identify the stages as homeostasis, the transition from order to chaos (destructurization), dynamic chaos, the transition from chaos to a new order (self-organization) (Budanov, 2013 p.47-63.). In the conception of Anaximander, all things arise from apeiron and everything will come back to it. Prigogine and Stengers believe that chaos is a building material for the formation of new systems, like apeiron. Chaos is a neutral stuff for construction the things. The order, as well as chaos, is never complete (Budanov, 2013 p.48). Let us remember that apeiron "embraces everything", that it exists in the things and around them. Finally, let us note that the concept of self-organization requires a control mechanism inherent to the system itself. Apeiron just "controls everything", which means, it directs processes of self-organization and deconstruction. The difference between the conceptions of Prigogine and Anaximander, of course, exists. What is more, it is not only in the degree of development and the presence or absence of mathematical support. However, we have tried to show exactly similar features.

Spinoza, a Dutch philosopher of the 19th century, believes that there is only one substance, and it has a lot of attributes, but men can perceive two of them - extension and thought. If we think of the world as an extended, it is Nature, if we think of the world as having consciousness it is God. The person is a part of a single substance. If you think about the person under the attribute of mind, it is a soul, and if you think about the person under the attribute of extension, it is a body (Spinoza, 1970 p.350-400; Priest, 1991 p.154-161).

This is not an evolutionary version of neutral monism. Regardless of whether such ontology involves an act of creation of the world, or not, the mental and the physical do not segregate with the time of a single substance, but always present in it as its inherent properties - attributes. Russell wrote in the first half of the 20th century that the concept of substance, which had adhered Spinoza, was not compatible with the modern science (Russell, 1946 p.601). Spinoza's ontology is closer to the Newtonian picture of the world than to modern relativistic physics and cosmology.

In the opinion of Bertrand Russell, an English philosopher of the 20th century, the universe is made up of events the space-time entities that have some great and extension. They are neither mental nor physical (Russell, 1927 p.287) and are not made of any substance (Russell, 1927 p.290). Matter and consciousness in the universe are constructed of this simple neutral material. It is in them and above them, like a common ancestor (Russell, 1921 p.10-11). Sensory data is the kind of events. They are neutral relatively to the mental and physical description. It is a meeting of psychology and physics. Sensory data (color, sound, smell, taste) may be conceived as mental when psychologists explain them by psychological laws. The same data is considered as physical when physicists explain them using the laws of physics. There will be neither the concept of "matter" nor of "mind" in a well-developed science, because the first of them does not mean anything and the second is very vague (Russell, 1927 p.292). Psychology and physics, studying the mental and physical phenomena show in the 20th century, according to Russell, two opposite trends: the psychology demonstrates materialistic orientation, and physics demonstrates anti-materialistic orientation. These trends need to be accepted by a modern philosophy (Russell, 1921 p.6).

Russell does not write anything that is contrary to the physics of his time (Priest, 1991 p. 163,170). It should be added that the ontology of Russell is consistent with scientific theories and facts which the English philosopher could not know. Inflationary models - modern versions of the Big Bang theory that describe the initial stages of the expansion of the Universe, were proposed in the 80th years of the 20th century. Russell's work "An Outline of Philosophy", "The Analysis of Mind", "The Analysis of Metter", which sets out the view that the "neutral stuff" (Russell, 1921 p.6), which are constructed from the mental and the physical are events, were written much earlier. Meanwhile, modern cosmology 
suggests that within the evolution of the Metagalaxy the Event - Big Bang - had occurred before the emergence of matter. According to inflation theory of A.D. Linde, within the first fractions of the second after the Big Bang, the universe expanded at a rate, significantly exceeding the speed of light. It is believed that this statement does not contradict the theory of relativity, as the space itself expanded (Linde, 2007). In accordance with the quantum Zeno effect, the characteristics and the lifetime of the elementary particle (particle of matter) also depend on the event - the act of observation of the particle (Halfin, 1990). The quantum Zeno effect was predicted in the $50^{\text {th }}$ years of the 20th century, but it was experimentally proved only in 1989. In view of modern cosmology, ontology of Russell can be seen as evolutionary.

Thus, in the ontology of Russell, the substantial and the genetic origin of the world are events. Meanwhile, the events may be considered as moving systems of relations, that is, structures that are in constant motion. This ontology is well consistent with the hypothesis of birth of matter proposed by Prigogine on the basis of synergetics. In their opinion, the condition for the appearance of the Universe was a sharp increase of entropy, which is within the decay of something highly organized. Next, as a result of spontaneous fluctuations of chaos (the physical vacuum, that is, a field in which there are only power lines and no particles) event occurred: the energy of the field began to generate particles of matter. (Prigogine, 1996). In other words, matter is generated by the moving structure (fluctuating vacuum). An event in this context is a qualitative leap in the process of vacuum fluctuations.

Consequently, events of Russell and chaos of Prigogine are moving structures without matter. These substances (chaos and events) are the sources of things. They exist in them and around them, have mechanisms of selforganization. At first glance, it seems that chaos of Prigogine in contrast to Apeiron of Anaximander and events of Russell has no relation to consciousness, but this is not true. Attractor (a target program), inherent to any complex system at the stage of homeostasis, and the phenomenon of self-organization brings the mental aspect to any complex open system, including vacuum (chaos).

The analysis shows that the only type of ontology, which corresponds to the principles of rationality, consistency, and modern evolutionism, is an evolutionary version of neutral monism.

\subsection{Main approaches to world history in their relation to the basic principles of the evolution of complex open systems}

In modern literature, one can reveal several historiosophical paradigms. A stadial approach includes the theory of socioeconomic formations (Karl Marx), the conception of modernization, created by Western sociologists after World War II, the theory of post-industrial society (Daniel Bell and other), and a number of other theoretical constructions. Civilizational paradigm combines the conception of many independent civilizations (Oswald Spengler, Arnold Toynbee, and other), the theory of two worlds (Max Weber), and the theoretical constructions of Nikolay Danilevsky, Leonid Vasilyev, Lyubov Semennikova that connect independent civilizations in a few models of historical evolution.

An approach of historiosophical synthesis incorporates the theories of dependent development, including the world-systems analysis (Fernand Braudel, Immanuel Wallerstein, Andre Frank and others); the conception of Alexander Panarin, who believed that world history is a rotation of leadership of the East and the West; the conception of global stages of historical evolution (Yuri Semenov). The essence of the latter theory consists of the statement that humanity as a whole, but not individual societies, are in their development of such stages as socio-economic formations. A synthesis paradigm may also include a theory of world cycles (Yuri Yakovets), although it is more combined than synthesis.

Let us denote the main characteristics of complex open systems and the basic principles of their evolution to determine which conceptions - stadial, civilizational or synthesis are in accordance with the key principles of synergetics.

The majority of real systems are open; their interaction with the environment cannot be ignored (Prigogine, Stengers, 2009 p.16.). If we apply this description of real systems to the human communities, we can see that each individual society feels important influences from other societies and, in turn, affects the surrounding social world. Thus, humanity is presented as a complete system and individual societies, regions, or civilizations are its elements. Therefore, corresponding to this description of complex systems a constructive approach to history must consider the evolution of human civilization as a whole.

At first glance, this is an argument in favor of a stadial approach, based on the identification of common patterns of social evolution. However, the need to take account of external factors makes improbable suggestion that all social organisms evolve generally in the same way. Thus, the recognition of the fact that social systems are open is an argument against the classical stadial approach and, in part, in favor of civilizational approach to history. However, a statement of the interdependence of societies makes this statement of synergetics fully compatible only with the synthesis paradigm. 
Increasing the degree of order in the system is always at the expense of the disorder in their environment (Prigogine, Stengers , 2009 p.52-53). The concept of "environment" can be interpreted as a set of societies which this social organism has contacts with. In this case, the simultaneous rapid development of all human societies is not possible. In part, this is an argument in favor of conception of Spengler. In contrast to Toynbee, Spengler believes that civilizations (the great cultures) exist on some social background. This principle of synergetics is not compatible with the classic stadial approach, although it can explain a backlog of some communities. This principle asserts the interdependence of societies and the development of some societies by the withdrawal of resources from others. Precisely this view is typical for theories of dependent development, including the world-systems analysis.

The majority of real systems are chaotic, which is, having the forecast horizon, and allowing only a probabilistic description as a whole that cannot be reduced to a dynamic description of the individual trajectories and waves (Prigogine, Stengers, 2009 p.12-13). If we assume that the mankind is a complete system, as it follows from the principle of the openness of human communities and of the approval of the development of some societies at the expense of others, then the principle of randomness makes sense to take it to human civilization as a whole. In this case, the definition of chaotic systems, cited above, calls into question the desire of many historians and philosophers to identify the stage of human evolution with the stages of the development of particular societies, therefore, humanity as a whole has its own laws, not reducible to the laws of the specific historical organisms. The authors of synthesis conceptions consider human evolution in this way.

Selection of one of the possible ways of evolution is determined by random factors; therefore, identical systems can choose different scenarios (Prigogine, Stengers, 1986 pp.216-217). This thesis clearly justifies the multi-variant historical evolution and seems to support civilizational approach to history. However, the principles outlined above require consider humanity as a complete system. All synthesis conceptions certainly reveal some models of historical development and the patterns of evolution of mankind in general.

The transition from "order" to "chaos" and from "chaos" to a new "order" shows us that complex open systems exist in a cyclic mode (Prigogine, Stengers, 1986 p.225). Consequently, humanity as a whole and the individual social organisms (nations, states, civilizations) evolve by cycles. The supporters of the civilizational approach to history always follow the idea of cycles, but in the classical civilizational conceptions they are local and do not lead to social progress. Meanwhile, a cycle in synergetics is a way of development. All synthesis conceptions interpret the development of humanity through a rotation of world cycles, although the concept itself may be absent. When applied to a specific society, this principle also requires taking into account the change of the subject of history, which was fully implemented in the conception of Semenov (Semenov, 2003 pp. 250-258, 425-508).

The analysis shows that the most prevalent classic stadial approach is incompatible with the principles of synergetics. An idea that all historical organisms pass the same steps that are also stages in the evolution of humanity as a whole seems to be abandoned.

As for the civilizational approach to history, it gets from synergetics a considerable support. Many principles of the evolution of complex open systems lead to the conclusion that different societies, regions or civilizations develop in different ways. However, the classical civilizational paradigm claims that there is no interaction and continuity between civilizations.

Meanwhile, the fact of isolation on the Earth (humanity is the maximum social system), combined with the assertions of the openness of real systems (individual societies) and increasing the degree of order in the system (individual society) due to the growth of disorder in its environment (other societies), leads to the conclusion that mankind should be considered as a single system. If this is true, a principle of randomness is applicable to the humanity in general. What is more, the principles of synergetics are fully compatible only with synthesis approach to history, claiming that specific societies (ethnic groups, regions, civilization), and mankind in general have different patterns of evolution. Individual societies evolve in different ways, and because of this there are many different societies, their clustering is possible and useful. In other words, the desire to reveal macro-structure of humanity receives the methodological basis thanks to synergetics.

Thus, we must conclude that synthesis approach to history is in accordance with the basic principles of the evolution of complex open systems to a greater extent than any other historiosophical paradigm. 


\section{Results, discussions, and recommendations}

\subsection{Neutral monism as low-level methodology of history}

It can be argued that the evolutionary version of neutral monism meets the key principles of synergetics and modern conceptions of the Universe's evolution to a greater extent than any other type of ontology. Therefore, an evolutionary version of neutral monism can be seen as a constructive low-level historical methodology.

However, the types of ontology and particular conceptions can be considered not only in terms of compliance with modern evolutionary theories. According to Priest, the main drawback of neutral monism is uncertainty regarding the nature of the postulated neutral entities (Priest, 1991 p.153). In part, this is acceptable. Science does not know such substance as apeiron. If we identify apeiron and chaos, a phenomenon like apeiron as well as events of Russell is more a state of a substance than the substance itself. Nevertheless, as we mentioned above, apeiron and events may be considered like variable structure (vacuum) that can give rise to matter and mind. However, it is a logical conclusion and not a statement of the philosophers themselves. It would be desirable to design a new modern conception in the framework of neutral monism. Perhaps it could be a generalization and a further development of theories of Anaximander, Russell, and Prigogine.

\subsection{Paradigm of historiosothical synthesis as top-level methodology of history}

As it has been proved, a synthesis approach to history collocates with the main principles of synergetics to a greater extent than stadial and civilizational approaches. Thus, synthesis paradigm can be proposed for the role of the top-level methodology of history. This paradigm assumes that the patterns of historical evolution of mankind as a whole and of individual societies are different, so the stages of development of a given society and the stage of human evolution are not the same. The authors define the models of historical development that are typical for different groups of societies and the stages of human evolution as a whole.

However, such version of methodology is constructive only when we believe that humanity has always been a unified system. Meanwhile, some researchers believe that the human race did not constitute a social system up to a certain point, probably up to the 16th century. Until this time, individual societies developed independently (Shishkov, 2005).

However, the period when all the communities were completely isolated from each other, did not exist even in the days of anthropogenesis. Archaeologists note a surprising similarity of tools and technology at all prehistoric campsites of archanthropines and paleoanthropes in the Lower Paleolithic period. It seems to show the presence of the exchange of information between the ancient human groups. A.V. Korotaev, A.S. Malkov and D.A. Halturina believe that the hyperbolic trend of growth of the human race watched from the tenth millennium before Christ and up to 1973 supports the hypothesis that humanity was a unified system since the Neolithic revolution (Korotaev, Malkov, and Halturina, 2010). The existence of a general network "did not preclude the gradual formation of local civilizations" (Bondarenko, 2009). Semenov clearly shows that if even more primitive Homo sapiens groups were significantly different from each other by the nature of their social organization, and it determines a variety of ways for their further evolution (Semenov, 2003 p.4650).

Let us note that the historiosophical approaches can be seen not only in their relation to synergetics. Each of them claims to be an adequate reflection of historical reality. However, it is very difficult to evaluate this aspect of historiosothical conceptions, trying to relate the speculative construction and historical facts. Formulating this problem very short, it can be argued that all existing approaches to history are partly, but not fully supported by interpreted in a certain way historical knowledge. Therefore, the requirement of correspondence between historiosophical paradigm and historical reality cannot help us selecting the most meaningful approach to history nowadays. This means that the appeal to the modern theory of evolution in order to choose only one approach offers a way to solve the problem.

Finally, we note that all synthesis conceptions have their advantages and disadvantages. Therefore, in frame of synthesis approach, it is advisable to carry out a further research of the most constructive historiosophical conception of world history.

\section{Conclusion}

Thus, an attempt to promote the translation of historiosothical paradigms from the category of philosophical doctrines to 
the category of scientific theories has led to the concretization of the ontological aspect of the historical methodology. According to this study, ontological aspect of historical methodology should combine a new evolutionary version of neutral monism, universal theories of evolution, based on modern science, and the conception of world history, developed in the future as a part of the synthesis approach to history. The evolutionary version of neutral monism and the synthesis approach to history are proposed as methodology of the history of the lower and upper level because they are in accordance with patterns of evolution that complex open systems and the Universe in general seem demonstrate.

\section{References}

Anaximander (1969). In Anthology of World Philosophy. Vol.1. (pp.270-273). Moscow: Misl (Thought).

Spinoza (1970). In Anthology of World Philosophy. Vol.2. (pp. 350-408). Moscow: Misl (Thought) .

Bondarenko, D.M. (2009). World-systemic and civilizational approaches: the opposition or complementary? In History and Synergetics: research methodology (pp. 7-16). Moscow.: "LIBROKOM".

Budanov, V.G. (2013). Methodology of synergetics in the post-nonclassical science and education. (4th ed.). Moscow: "LIBROKOM".

Grinin, L.E. (2006). The periodization of history: theoretical and mathematical analysis. In History and Mathematics: the problem of macro-historical periodization. (pp. 53-79). Moscow: KomKniga.

Finkelberg, A. (1994). Plural Worlds in Anaximander. The American Journal of Philology, 115, 485-486.

Kapitsa, S.P., Kurdyumov, SP, and Malinetskiy, G.G. (2003). Synergetics and projections of the future (2nd edition). Moscow.: "LIBROKOM".

Knyazeva, E.N., Kurdyumov, S.P. (1994). Synergetics as a tool for integration of science and humanities. Higher education in Russia, 4, 31-34.

Korotaev, A.V., Malkov A.S, Halturina D.A. (2010). The compact mathematical macro model of techno-economic and demographic development of the World System (1-1973). In History and Synergetics: mathematical models of social, economic, and cultural dynamics. (pp.5-48). Voscow: KomKniga.

Linde A.D (2007). Many faces of the universe (the text of the lecture). June 10, Moscow, FIAN. [Online] Availabless: http://elementy.ru/lib/430484 (June 30, 2013)

Nefedov, S.A. (2002). Experience in modeling the demographic cycle. Newsletter of association "History and Computer ", 29, 131-142.

Prigogine, I.R., Stengers, I. (1986). Order out of chaos. Translated from English. Moscow: Progress.

Prigogine, I. (1996). Le temps précède-t-il l'existence? In Prigogine, I. La fin des certitudes (pp.189-214). Paris: Odile Jacob.

Prigogine, IR, Stengers, I. (2009). Time. Chaos. Quantum. (Reprint). Translated from English. Moscow: "LIBROKOM".

Priest, St. (1991).Theories of the mind. London, New York, Ringwood: Penguin group.

Popper, K. (1979). Is there a law of evolution? Laws and trends. In Popper, K. The Poverty of Historicism (pp. 105-119). (2d ed. revised and enlarged). London and Henley: Poutledge and Kegan Paul.

Rozov, N.S. (2002). Philosophy and theory of history. The first book. Moscow: Logos.

Russell, B. (1921). The Analysis of Mind. London: George Allen and Unwin.

Russell, B. (1927). The Analysis of Matter. London: Kegan Paul.

Russell, B. (1946). History of Western Philosophy. London, George Allen and Unwin.

Semenov, Y.I. (2003). The philosophy of history. Moscow: Sovremennie tetradi (Modern notebooks),

Turchin, P. (2003). Historical Dynamics: Why States Rise and Fall. Princeton University Press.

Halfin, L.A. (1990). The quantum Zeno effect. Advances of Physical Sciences, 160, Issue 10, 185-188.

Shishkov, Y. V.(2005). Demographic adventures of a physicist. Social Sciences Today, 2, 156-161. 